\title{
VI - O Futuro da Administração Internacional
}

O mundo - por imperativo de sua própria sobrevivência - caminha inexoravelmente, de bom ou de mau grado, para uma era de crescente cooperação internacional, em substituição à era de impiedosa e desumana competição internacional, que prevaleceu, até agora, de modo predominante, nas relações entre os povos.

Isso decorre, necessariamente, acima de tudo, do tremendo desenvolvimento das armas de guerra, com o aparecimento dos artefatos nucleares, e da necessidade de se procurar preservar deles a humanidade.

Como é óbvio, tudo indica que o planeta terra está tentando a primeira via, a da cooperação internacional.

A evidência disso acha-se em fatos concretos e positivos de natureza política e administrativa.

Politicamente, assistimos, entre outros eventos marcantes, à busca de entendimentos entre as duas superpotências, à quebra do isolamento da China em relação ao resto do mundo e ao clima geral de distensão que se procura estabelecer no globo.

Administrativamente, testemunhamos, de forma paralela, o surgir de um número cada vez maior de organismos internacionais e de empresas multinacionais, a trabalharem, desinteressadamente ou com fins lucrativos, em toda a face da terra, interligando povos, culturas, religióes, crenças e aspirações.

A própria Igreja, com o seu "aggiornamento" e o seu ecumenismo, participa desse movimento, como nem podia deixar de ser, buscando o diálogo com os'fiéis de outros credos e até mesmo com os não-crentes.

Em suma, a política, os negócios, as crenças, internacionalizam-se, cada vez mais, abandonando velhos tabus, incompatibilidades e nacionalismos intransigentes.

Ou, como se expressam Keith e Gubellini, já tantas vezes citados:

"We are aware that, in terms of time, the earth continues to shrink in size; and little by little we are forced to think more in global terms than national terms." (47). 
Como resultado, conforme vimos nas páginas precedentes, surgiu, na face da terra, em nosso século e, especialmente, nos últimos vinte e cinco anos, uma administração internacional, que está sendo exercitada, na prática, pelos organismos internacionais e pelas empresas multinacionais, cujo número, em ambos os casos, como também vimos, cresce de dia para dia.

Importa e urge, agora, analisar esse fenômeno, como já o estão fazendo numerosos tratadistas e estudiosos da matéria, sobretudo nos Estados Unidos, e extrair dessa análise as lições doutrinárias que ela comporta.

Ou, segundo as palavras de Franklin R. Root, vendo o problema do prisma das empresas multinacionais :

"Todo o âmbito das funções da alta gerência e dos negócios, com as suas múltiplas interações em relação aos aspectos econômicos, políticos e culturais de um ambiente internacional complexo e cambiante, já é trigo para o moinho do educador (is now grist for the educator's mill, expresão típica norte-americana, principalmente dos meios universitários, para indicar que algo está maduro para estudo). Pois, há clamorosa necessidade de bases conceptuais que nos ajudem a relacionar os vários e aparentemente disconexos elementos dos negócios internacionais em um conjunto compreensivo e harmônico." (48) .

A administração internacional - sobretudo, pelas razões expostas, no que concerne aos recursos humanos - é, assim, sem sombra de dúvida, uma nova dimensão da administração em nossos dias.

E - salvo a eventualidade apocalíptica de uma hecatombe nuclear, que destruiria, então, os próprios fundamentos da civilização - o seu rápido e progressivo desenvolvimento se acha plenamente assegurado. Pois, a cooperação internacional que já caracteriza a nossa época tende a crescer cada vez mais, entrelaçando nações em esforços comuns para lutar contra os verdadeiros inimigos da humanidade, que são a fome, a miséria, a ignorância, a doença, e não os povos entre si.

Em conseqüência, as organizações internacionais de modo geral, sejam do tipo dos organismos internacionais propriamente ditos, sejam do tipo das empresas ou corporações multinacionais, vão se multiplicar e proliferar cada vez mais, exigindo um número crescente de administradores e funcionários internacionais altamente qualificados para equacionar e solucionar os tremendos e complexos problemas que esse novo tipo de convivência mundial exige, principalmente do administrador e, em especial, do administrador de recursos humanos.

(48) John Fayerweather, Op. cit., p. vii (Editor's Foreword).

R. Serv. públ., Brasília, 109 (4) out./dez. 1974 
Daí o haver escrito com muita razão eminente autor norte-americano:

"Se o movimento no sentido das operações internacionais continua como se processa atualmente, calcula-se que mais da metade dos graduados universitários em administração de empresas (dos EE.UU.) dedicar-se-ão por toda a sua vida a tais atividades. Com a crescente ênfase nos negócios internacionais, os estudantes interessados em administração de pessoal terão necessidade de estudar e compreender os problemas peculiares ligados à obtenção e gerência de pessoas para operações internacionais, pois o processo de internacionalização afeta todos os campos de atividades de uma empresa, mas, em particular, o de pessoal." (49) .

Há, assim, necessidade de preparar amplos contingentes das novas gerações para esse novo tipo de administração, aparelhando-os com instrumental lingüístico apropriado, com aprofundados conhecimentos da história e da geografia humanas, com uma visão larga dos problemas mundiais, compreensão e simpatia por outras culturas e tipos diferentes de civilização, sem o que as funções internacionais, sejam de que tipo forem, não podem ser convenientemente exercidas.

Há, em suma, a necessidade de preparar as novas gerações para a administração internacional pois ela, ao que tudo indica, será a sua administração, ou seja, a administração de nossos filhos e nossos netos.

Este livro, como foi dito nas Palavras Preliminares, é modesta e sucinta tentativa nesse sentido. E o autor se dará por amplamente recompensado se o seu esforço contribuir, por qualquer forma, para a intensificação dos estudos da administração internacional, entre nós, e, em especial, da administração internacional de recursos humanos.

(49) Leon C. Megginson, Personnel: A Behavioral Approach to Administration, Homewood, Illinois, Richard D. Irwin, Inc., revised edition, 1972, p. 701. 


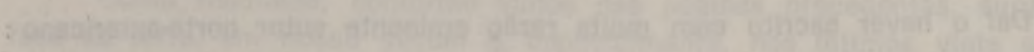

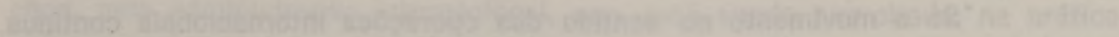

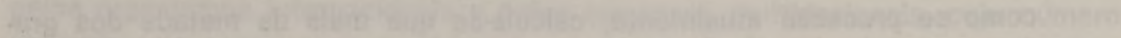

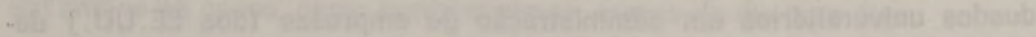
wathing of

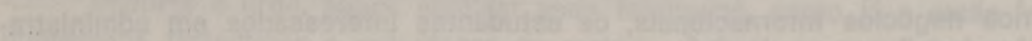

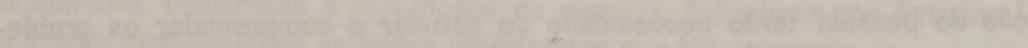
.030

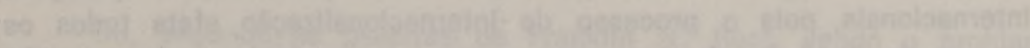

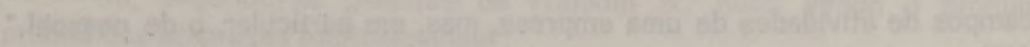

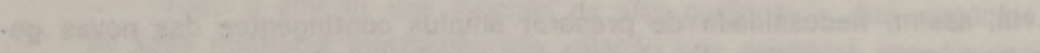

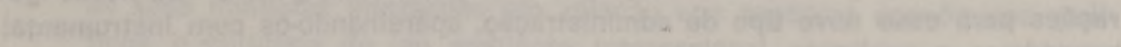

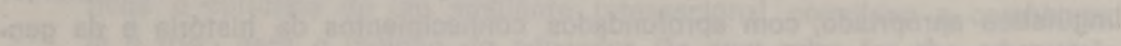
C16.1. E.

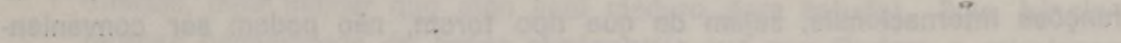

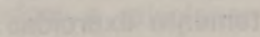

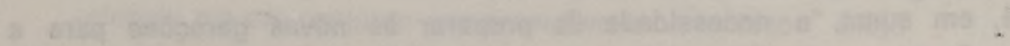

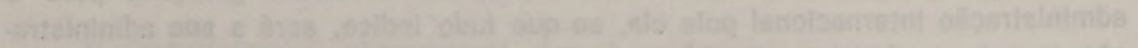
I.

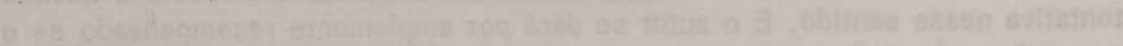

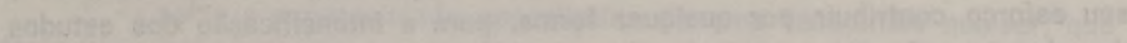

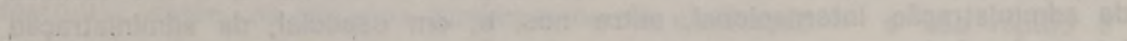

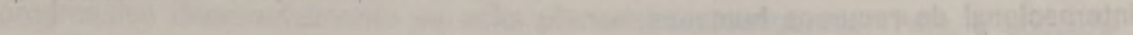

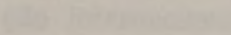

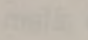

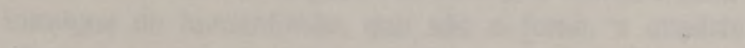
(2)

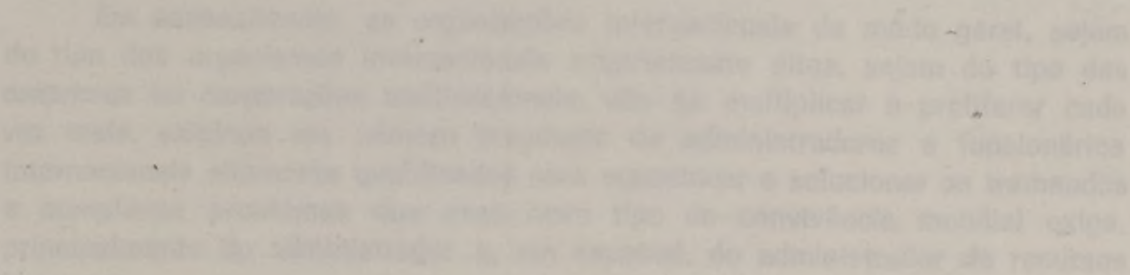
(3) [1:

What (n:S) $5 \cdot 3=2$

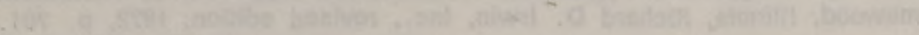

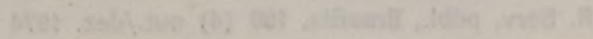

